\title{
MAPPING AUSTRALIAN GEOPHYSICS: A CO-HEADING ANALYSIS
}

\author{
R. TODOROV,* M. WINTERHAGER** \\ *Centre for Scientific Information, Bulgarian Academy of Sciences \\ BG-1040 Sofia, 7 Noemvri St. (Bulgaria) \\ **Science Studies Unit, University of Bielefeld \\ D-4800 Bielefeld 1 (FRG)
}

(Received August 21, 1989)

\begin{abstract}
Descriptive capacities of a new bibliometric method, namely co-heading analysis, are investigated. The method uses the appearance and co-appearance of classification subdivisions (headings) in the document records of 1988 INSPEC database to display correspondingly the main topics of Australian geophysics and their links. The findings, in the form of inclusion maps (resulting from multidimensional scaling and cluster analysis). provide new insights into geophysics national activity and into its structure.
\end{abstract}

\section{Introduction}

National research efforts (publication activity and impact) in a given (sub)field of science are increasingly represented by author participation in research fronts as determined by co-citation cluster analysis. ${ }^{1}$ The results of such analysis in terms of highly-cited (core) documents and their links (as reflected in a set of recent journal articles) have been first considered for science structure representation and further as tools for research management and evaluation. ${ }^{2}$ At the same time criticisms have been expressed concerning theoretical conceptions and techniques applied. ${ }^{3-7}$ However, the idea of counting co-appearances of highly-cited publications, ${ }^{8}$ words, 9 and authors ${ }^{10}$ and representing them in an appropriate manner is attractive in the sense that it offers an opportunity (at least) to discuss directly quantitative (bibliometric and/or scientometric) results with experts.

The aim of this paper is to investigate a recently proposed bibliometric method ${ }^{11}$ as a new tool and the INSPEC file as an appropriate source of information for studying the structure of scientific subfields. The specific purpose is to extract nontraditional data on Australian geophysics publications (such as subject and research characteristics, distribution over institutes and journals, etc.) and to represent the most frequently appearing topics in Australian geophysics papers in an appropriate 
manner as well as their interrelationships as depicted in different subsets of documents.

\section{Data and method}

Data for geophysics research have been extracted from the INSPEC (Information Services for the Physics and Engineering Communities) file which contains records for the world-wide literature on physics (as well as on electricity and electronics, and computer science). Together with traditional bibliographic data, an INSPEC record includes (see Table 1) a set of elements expressing the subject content of a document: Classification Codes (CC), Treatment Codes (TC), and (Controlled or Supplementary) Terms. CC stand for subject headings or topics which fall into the following categories:

- substances (or named objects) and characteristics (properties);

- phenomena, processes, effects, etc.;

- theories, methods, models;

- instruments and techniques.

The CC are assigned to documents by indexers (or by the authors themselves) according to the International Classification for Physics (ICP). ${ }^{12}$ (These CC are later used for retrieval and generating cross-references for the printed version.)

The TC indicate the nature of the subject treated in a document (theoretical, applied, review, etc.).

For the purpose of the study all documents containing any code for geophysics and an address of an university or institute in Australia have been downloaded from the 1988 INSPEC A file (printed version: Physics Abstracts). A total of 224 geophysics papers have been extracted. Four record fields of the downloaded file have been selected for quantitative analysis: CC,DT (Document Type). TC, and AU (Author and affiliation). The following six sets of records have been then produced:

- one including all Australian geophysics publications (original file of 224 documents).

- two subsets from the previous file containing correspondingly experimental and theoretical papers only.

- three sets covering the geophysics subdivisions: solid Earth geophysics (SEG), hydrospheric and atmospheric geophysics (HAG), and geophysical observations and techniques (GOT). 
Table 1

Sample record of 1988 INSPEC file

\begin{tabular}{ll}
\hline Field* & \multicolumn{1}{c}{ Data } \\
\hline TI & $\begin{array}{l}\text { Plate boundary tectonics, global sea-level changes and the } \\
\text { development of the eastern South Island continental margin, New } \\
\text { Zealand,southwest Pacific. }\end{array}$ \\
AU & $\begin{array}{l}\text { Carter, R.M. (Dept. of Geol., James Cook Univ., Townsville, Q1d., } \\
\text { Australia) }\end{array}$ \\
SO & $\begin{array}{l}\text { Marine and Petroleum Geology (May 1988) vol.5, no.2; p. 90-107; } \\
\text { 126 refs. CODEN: MPEGD8 ISSN: 0264-8172 }\end{array}$ \\
DT & Journal \\
LA & Bibliography; General Review \\
CC** & English \\
CT & 5A9145D; 5A9330K; 5A9330F; 5A9330P; 5A9210H \\
ST & OCEONOGRAPHY; TECTONICS \\
& $\begin{array}{l}\text { plate boundary tectonics; Gondwanaland break up; Great South Basin } \\
\text { evolution; global sea-level changes; eastern South Island } \\
\text { continental margin; New Zealand; southwest Pacific; } \\
\text { seđimentary evolution; seismic sequences; stratigraphic sequence }\end{array}$ \\
\hline
\end{tabular}

*AUthor, SOurce, Document Type, Treatment Codes, LAnguage, Classification Codes, Controlled Terms, Supplementary Terms.

${ }^{* *}$ Assigned according to the International Classification for Physics:

SA9145D: Plate tectonics,

5A9330K: Large Islands,

5A9330F: Australia,

5A9330P: Pacific ocean,

SA9210H: Surface waves, tides and sea level.

An appropriate software has been developed for arranging the headings (or the $\mathrm{CC}$ ) in every set of records in descending order of their occurrence and for constructing triangular matrices $\mathrm{C}=\left\{\mathrm{C}_{\mathrm{ij}}\right\}$ containing the co-appearances of the top $\mathrm{n}$ headings. (Two headings $\mathrm{C}_{i}$ and $\mathrm{C}_{j}$ are said to co-occur if there is at least one record containing both $C_{i}$ and $C_{j}$ ) $A$ diagonal element $C_{i i}$ is the absolute frequency of 
appearance of $C_{i}$ and an off-diagonal element $C_{i j}$ represents the co-occurrence of $C_{i}$ and $C_{j}$ in the set of records under consideration.

The matrix $\mathrm{C}=\left\{\mathrm{C}_{\mathrm{ij}}\right\}$ is used for calculating an appropriate relative measure of similarity. Since the $C_{i}$ are elements of a (hierarchical) classification scheme, ${ }^{13}$ it is convenient to use like in co-word analysis ${ }^{14}$ the inclusion index $I_{i j}=C_{i j} / \min \left(C_{i i}, C_{j j}\right)$ for highlighting the "central poles" of Australian geophysics and reveal their relations with other "peripheral" topics. ${ }^{15}$ The $\mathrm{I}_{\mathrm{ij}}$ expresses the degree to which two headings are related . It is a measure of similarity as the highest values correspond to pairs that most co-appear in the given set of documents (records).

Once this measure has been determined, the final step consists in displaying (as a geometrical model or map) the structure of Australian geophysics research. Here, multidimensional scaling (ALSCAL program) is applied to display closeness of headings through their spatial configuration within a two dimensional representation. ${ }^{16}$ Since a representation of two dimensions is usually not enough to accommodate all interrelationships, the results of a hierarchical clustering are embedded in a map by constructing closed curves (loops) around headings that belong to the same cluster. "In this way the natural clusters are brought out in a more explicit and objective way for purposes of interpretation, labelling or comparison with independently obtained clusterings of the same objects." ${ }^{17}$ (p.40) Additionally, relation strength (based upon the inclusion index values) has been shown by connecting highly co-appearing headings (from the lower to the higher frequency of appearance) with corresponding line type.

\section{Results}

A list of geophysics headings which appear most frequently in Australian publications is given in Table 2. In Table 3 the Australian geophysics papers are subdivided according to their treatment codes (theoretical, experimental, applied, etc). Since more than one treatment code could be allocated to a document, their sum is greater than the number of records under consideration. In Table 4 the distributions of Australian geophysics papers are shown: over states, institutions and units. (They are based only on the first author address). In Table 5 the subset of journal articles is arranged according to the source journals. 
Table 2

Topics (headings) of 1988 Australian Geophysics according to the International Classification for Physics

\section{SOLID EARTH GEOPHYSICS}

Topography: geometrical observations

Harmonics of gravity potential field

Spatial variations

Seismology

Explosion seismology

Heat flow; geothermy

Structure of crust and upper mantle

Composition of Earth' $s$ interior
Geochronology

Volcanology

Plate Techtonics

Beach, coastal and shelf processes

Turbidity currents; sedimentation

Elasticity, fracture and flow

Geophysical aspects of geology, mineralogy and petrology

\section{HYDROSPHERIC AND ATMOSPHERIC GEOPHYSICS (HAG)}

Dynamics of the deep ocean

Dynamics of the upper ocean

Surface waves, tides, and sea level

Sea-air energy exchange processes

Turbulence and diffusion

Thermohaline structure and circulation

Coastal and estuarine oceanography

Modelling; general theory

Precipitation

Rivers, runoff, and streamflow

Erosion and sedimentation

Soil moisture

Limnology
Meteorology

Convection, turbulence \& diffusion

Boundary layer structure and

processes

Winds and their effects

Chemical composition and chemical interactions

Water in the atmosphere

Cloud physics

Climatology

Weather analysis and prediction

Other topics in HAG

\section{GEOPHYSICAL OBSERVATIONS, INSTRUMENTATION, AND TECHNIQUES}

Asia

Australia

Large islands

Indian Ocean

Pacific Ocean
Regional seas

Instrumentation and techniques

for geophysical research

Computer techniques 


\section{R. TODOROV, M. WINTERHAGER: MAPPING AUSTRALIAN GEOPHYSICS}

Table 3

Classification of Australian geophysics publications according to their Treatment Code (TC)

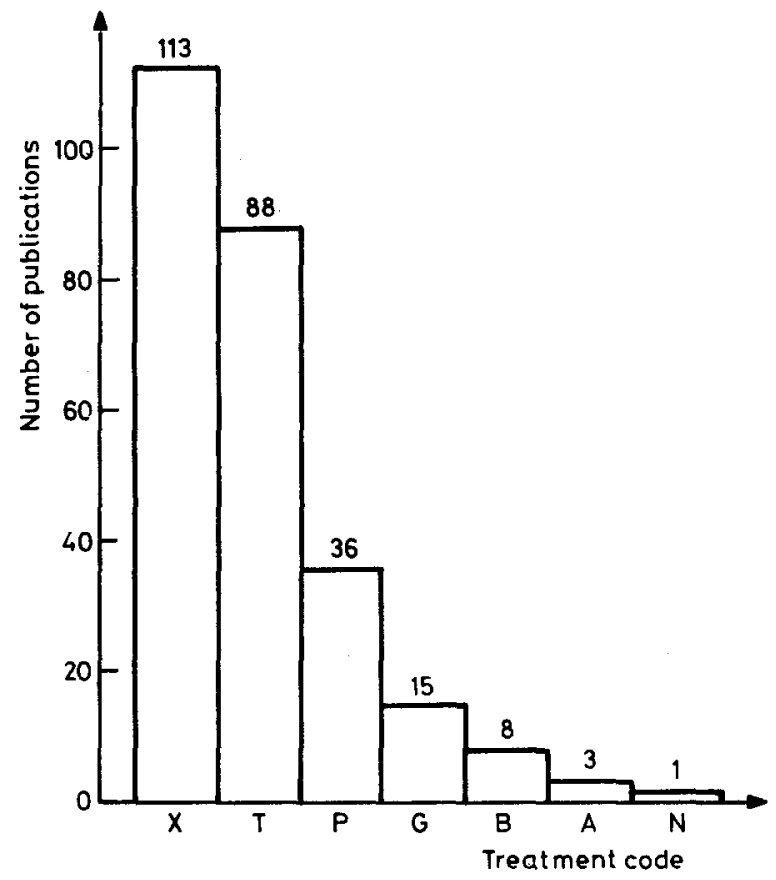

T THEORETICAL

B BIBLIOGRAPHY

G GENERAL

$X$ EXPERIMENTAL

A APPLICATION

N NEW DEVELOPMENTS

P PRACTICAL the treatment of subject is of a theoretical nature.

indicates documents with a bibliography or long list of references.

documents including general approaches, overviews, and reviews.

the document describes an experimental method, observation or result.

the document describes the actual or potential use of an instrument, device, method or technique, computer programme, or a physical effect where some specific application is described or envisaged.

a claim of novelty (in the patent sense) is made.

the document is intended to be of direct practical use and is linkely to be of interest particularly to engineering and design staff. 
Table 4

Georgraphical and institutional distribution of Australian geophysics publications

I. Geographical distribution over states and territories

\begin{tabular}{llc}
\hline Rank & State/Territory & $\begin{array}{c}\text { Number of } \\
\text { papers }\end{array}$ \\
\hline & Australian Capital Territory (ACT) & 63 \\
2 & Victoria (VIC) & 54 \\
3 & New South Wales (NSW) & 47 \\
4 & Western Australia (WA) & 18 \\
5 & South Australia (SA) & 15 \\
6 & Queensland (QLD) & 15 \\
7 & Tasmania (TAS) & 10 \\
8 & Northern Territory (NT) & 2 \\
\hline
\end{tabular}

II. Most productive Australian institutions in geophysics (according to 1988 INSPEC A database)

Number of Institutions

papers

46 Commonwealth Scientific and Industrial Research Organization

32 AUSTRALIAN NAT. UNIV, CANBERRA, ACT

20 BUR. OF METEOROL. RES. CENTRE, MELBOURNE, VIC.

15 NEW SOUTH WALES UNIV., KENSINGTON, NSW

14 BUR.OF MINER. RESOURCES, CANBERRA, ACT.

9 SYDNEY UNIV., NSW.

8 WESTERN AUSTRALIAN UNIV., NEDIANDS, WA.

7 FLINDERS UNIV., BEDFORD PARK, SA.

7 MELBOURNE UNIV., PARKVILLE, VIC.

7 MONASH UNIV., CLAY'TON, VIC.

7 QUEENSLAND UNIV., ST LUCLA, QLD. 
R. TODOROV, M. WINTERHAGER: MAPPING AUSTRALIAN GEOPHYSICS

(Table 4 cont.)

III. Most productive Australian units in geophysics (according to 1988 INSPEC A database)

\begin{tabular}{cl}
\hline $\begin{array}{c}\text { Number of } \\
\text { papers }\end{array}$ & \multicolumn{1}{c}{ Units } \\
\hline & \\
29 & RES. SCH. EARTH SCI., AUSTRALIAN NAT. UNIV., CANBERRA, ACT. \\
15 & DIV. ATMOS. RES., CSIRO, ASPENDALE/MORDIALLOC, VIC. \\
13 & DIV. GEOPHYS., BUR. OF MINER. RESOURCES, CANBERRA, ACT. \\
9 & DIV. ENVIRON. MECH., CSIRO, CANBERRA, ACT. \\
6 & DIV. OCEANOGR., CSIRO, HOBART, TAS. \\
6 & INST. ATMOS.\&MARINE SCI., FLINDERS UNIV., BEDFORD PARK, SA. \\
6 & SCH.MATH., NEW SOUTH WALES UNIV., KENSINGTON, NSW. \\
4 & DEPT. GEOL., WESTERN AUSTRALIA UNIV., NEDLANDS, WA. \\
4 & DIV. MINER. \& GEOCHEM., CSIRO, WEMBLEY, WA. \\
\hline
\end{tabular}

Table 5

Distribution of Australian geophysics articles over journals titles

\begin{tabular}{lll}
\hline Rank & $\mathrm{N}$ & Journal title (Country) \\
\hline
\end{tabular}

$1 \quad 19$ J. GEOPHYS. RES. (USA)

$213 \quad$ EARTH PLANET. SCI. LETT. (NETHERLANDS)

$3 \quad 13$ WATER RESOUR. RES. (USA)

$4 \quad 12$ MONTHLY WEATHER REVIEW (USA)

$5 \quad 10 \quad$ NATURE (UK)

$6 \quad 8 \quad$ AUST. METEOROL. MAG. (AUSTRALIA)

$7 \quad 7 \quad$ J. PHYS. OCEANOGR (USA)

$8 \quad 6 \quad$ J. ATMOS. SCI. (USA)

95 CONT. SHELF RES.(UK)

105 GEOPHYSICAL JOURNAL

114 APPLIED OPTICS (USA)

124 BMR J. AUST. GEOL. GEOPHYS. (AUSTRALIA)

134 GEOPHYS. RES. LETT. (USA)

$14 \quad 4 \quad$ GEOPHYSICS (USA)

154 TECTONOPHYSICS (NETHERLANDS)

163 BULL. AM. METEOROL. SOC. (USA)

173 COMPUT. GEOSCI. (UK)

183 DEEP-SEA RES. A, OCEANOGR. RES. PAP. (UK)

193 EARTH SURFACE PROCESSES AND LANDFORMS (UK)

203 IEEE TRANS. GEOSCI. REMOTE SENS. (USA) 
(Table 5 cont.)

\begin{tabular}{rll}
\hline Rank & N & \multicolumn{1}{c}{ Journal title (Country) } \\
\hline 21 & 3 & J. APPLIED METEOROLOGY \\
22 & 3 & PHOTOGRAMM. ENG. REMOTE SENS. (USA) \\
23 & 3 & SOLAR ENERGY (USA) \\
24 & 3 & TECTONICS (USA) \\
25 & 2 & AUST. J. GEOD. PHOTOGRAMM. SURV. (AUSTRALIA) \\
26 & 2 & BULL. SEISMOL. SOC. AM. (USA) \\
27 & 2 & CHEM. GEOL.: ISOT. GEOSCI. SECT. (NETHERLANDS) \\
28 & 2 & GEOJOURNAL \\
29 & 2 & GEOLOGY (USA) \\
30 & 2 & J. CLIMATOL. (UK) \\
31 & 2 & J. COAST. RES. (USA) \\
32 & 2 & J. GEOL. (USA) \\
33 & 2 & J. PETROL. (UK) \\
34 & 2 & J. QUANT. SPECTROSC. RADIAT. TRANSF. (UK) \\
35 & 2 & MAR. PET. GEOL. (UK) \\
36 & 2 & PRECAMBRIAN RES. (NETHERLANDS) \\
37 & 2 & SCIENCE (USA) \\
$38-68$ & 1 & Other 31 journals Publishing one article each. \\
\hline
\end{tabular}

The application of multidimensional scaling and hierarchical cluster analysis as complementary methods for highlighting closeness of headings is shown in the form of maps correspondingly on Figs 1-6. Symbol plots of the headings are explained in Table 6. On Figure 1 Australian geophysics is represented. Experimental and theoretical research are separately shown on Figs 2 and 3. On Figures 4-6 "zoom" or detailed maps are displayed for the three main geophysics subdivisions (SEG, HAG, and GOT) as covered by Australian research.

Table 6

Plot symbols used for topics (headings) of 1988 Australian geophysics

\begin{tabular}{cl}
\hline $\begin{array}{l}\text { Plot } \\
\text { Symbol }\end{array}$ & \multicolumn{1}{c}{ Topic } \\
\hline 1 & Australia \\
2 & Instrumentation and techniques for geophysics \\
3 & Structure of crust and upper mantle \\
4 & Geophysical aspects of geology, mineralogy and petrology \\
5 & Geochronology \\
6 & Coastal and estuarine oceanography \\
\hline
\end{tabular}




\section{R. TODOROV, M. WINTERHAGER: MAPPING AUSTRALIAN GEOPHYSICS}

(Table 6 cont.)

\begin{tabular}{|c|c|}
\hline $\begin{array}{l}\text { Plot } \\
\text { Symbol }\end{array}$ & Topic \\
\hline 7 & Pacific Ocean \\
\hline 8 & Plate Tectonics \\
\hline 9 & Dynamics of the upper ocean \\
\hline 10 & Composition of Earth's interior \\
\hline 11 & Regional seas \\
\hline 12 & Surface waves, tides, and sea level \\
\hline 13 & Winds and their effects \\
\hline 14 & Weather analysis and prediction \\
\hline 15 & Thermohaline structure and circulation \\
\hline 16 & Water in the atmosphere \\
\hline 17 & Meteorology \\
\hline 18 & Climatology \\
\hline 19 & Rivers, runoff, and streamflow \\
\hline 20 & Heat flow, geothermy \\
\hline 21 & Seismology \\
\hline 22 & Other topics in solid Earth geophysics \\
\hline 23 & Computer techniques \\
\hline 24 & Large islands \\
\hline 25 & Boundary layer structure and processes \\
\hline 26 & Asia \\
\hline 27 & Indian Ocean \\
\hline 28 & Beach, coastal and shelf processes \\
\hline 29 & Volcanology \\
\hline 30 & Cloud physics \\
\hline 31 & Convection, turbulence \& diffusion \\
\hline 32 & Precipitation \\
\hline 33 & Modelling; general theory \\
\hline 34 & Dynamics of the deep ocean \\
\hline 35 & Soil moisture \\
\hline 36 & Elasticity, fracture and flow \\
\hline 37 & Turbidity currents; sedimentation \\
\hline 38 & Other topics in HAG \\
\hline 39 & Topography: geometrical observations \\
\hline 40 & Spatial variations \\
\hline 41 & Harmonics of gravity potential field \\
\hline 42 & Explosion seismology \\
\hline 43 & Chemical composition and chemical interactions \\
\hline 44 & Sea-air energy exchange processes \\
\hline 45 & Limnology \\
\hline 46 & Erosion and sedimentation \\
\hline 47 & Turbulence and diffusion \\
\hline
\end{tabular}




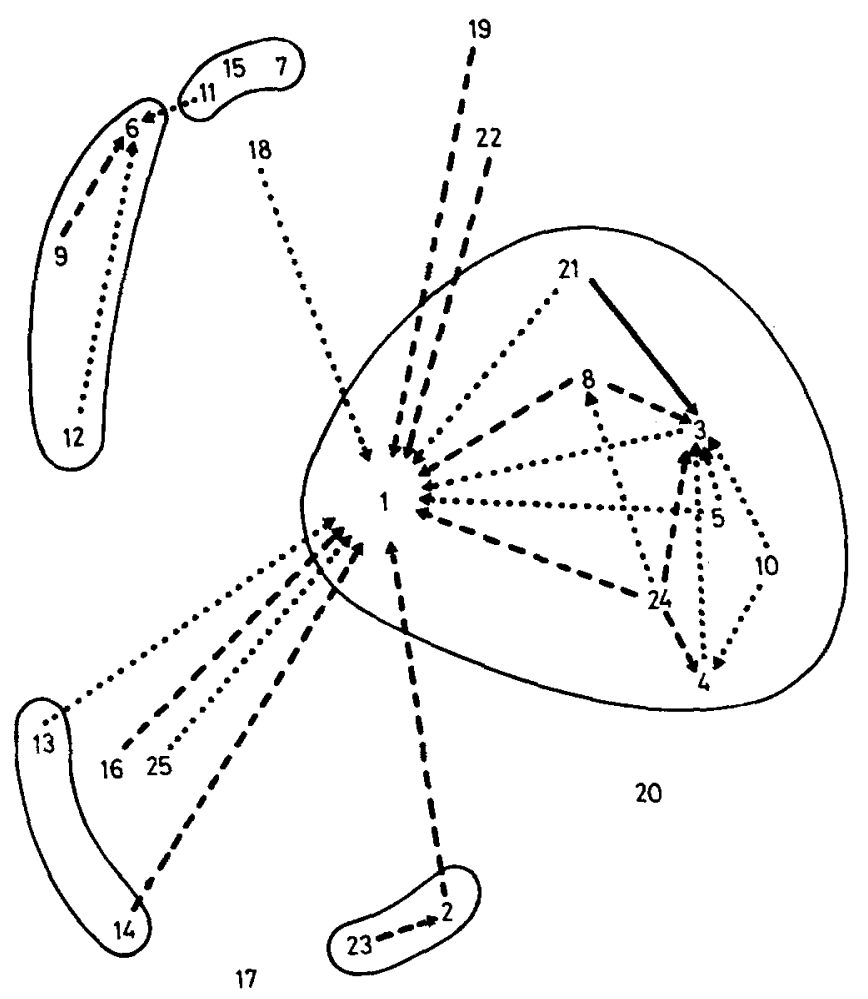

Fig. 1. Inclusion map for 1988 Australian geophysics. (Plot symbols are given in Table 6)

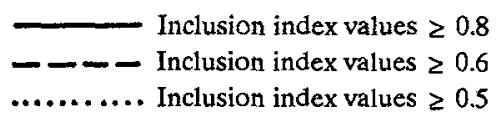




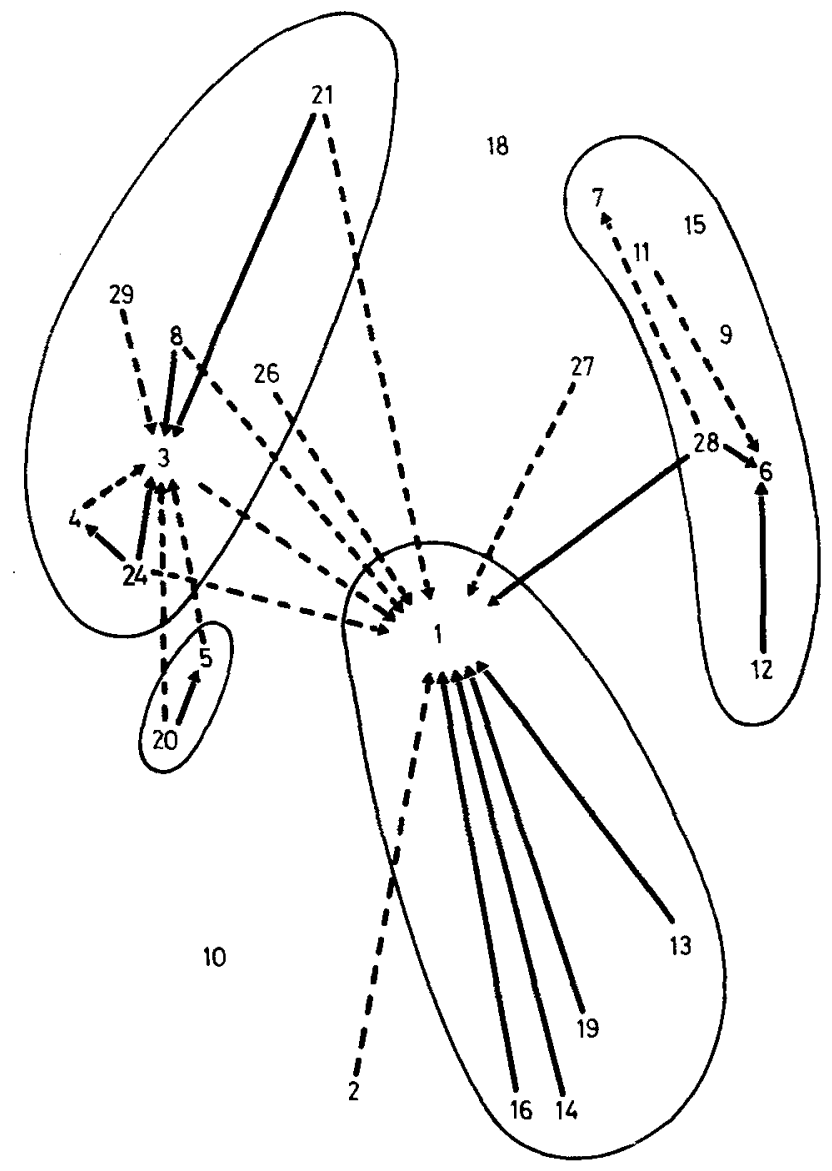

Fig. 2. Inclusion map for 1988 Australian experimentai geophysics. (Plot symbols are given in Table 6)

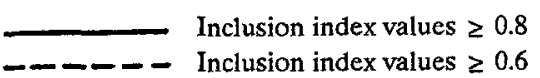



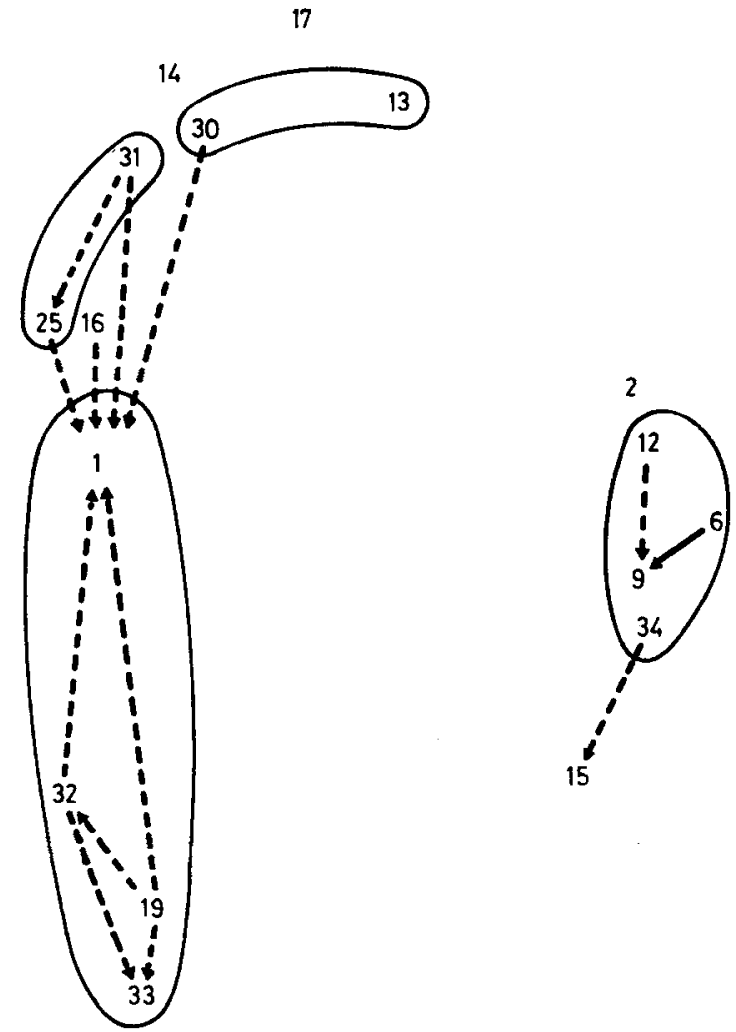

35

Fig. 3. Inclusion map for 1988 Australian theoretical geophysics. (Plot symbols are given in Table 6)

Inclusion index values $\geq 0.8$

$\ldots \ldots$ Inclusion index values $\geq 0.6$ 


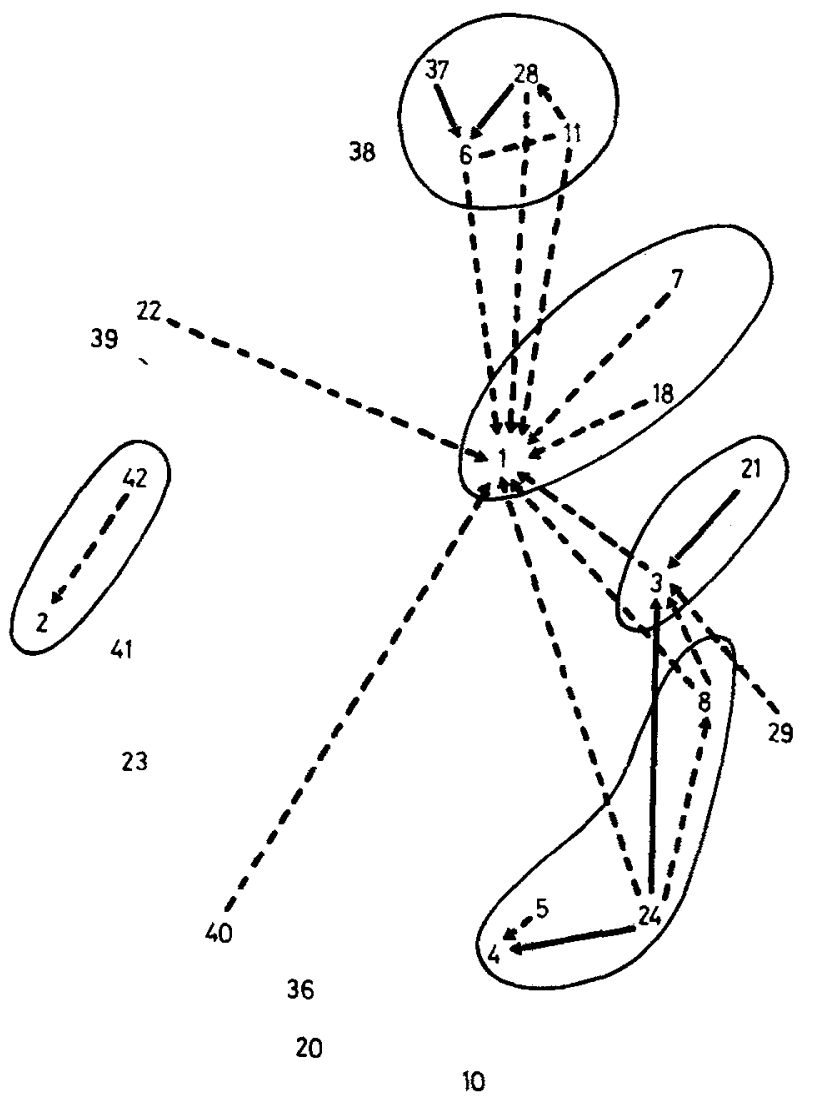

Fig. 4. Zoom map for 1988 Australian solid earth geophysics. (Plot symbols are given in Table 6) Inclusion index values $\geq 0.8$

- Inclusion index values $\geq 0.6$ 


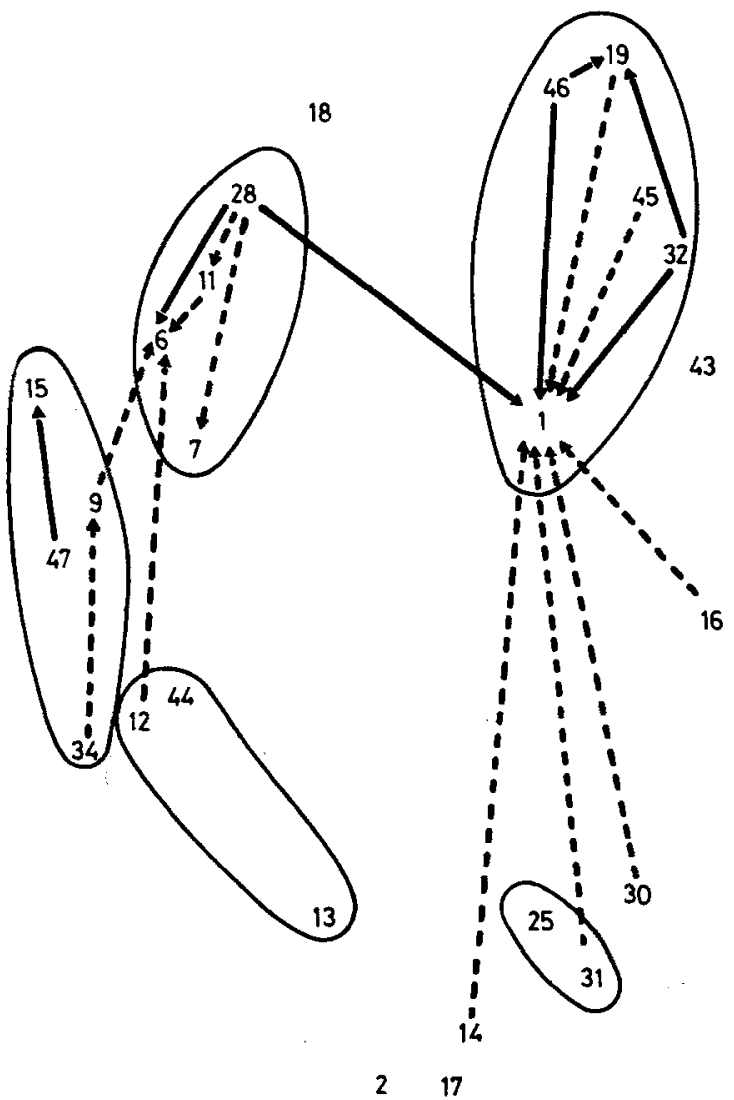

Fig. 5. Zoom map for 1988 Australian hydrospheric and atmospheric physics. (Plot symbols are given in Table 6)

Inclusion index values $\geq 0.8$

$\ldots \ldots$ - Inclusion index values $\geq 0.6$ 


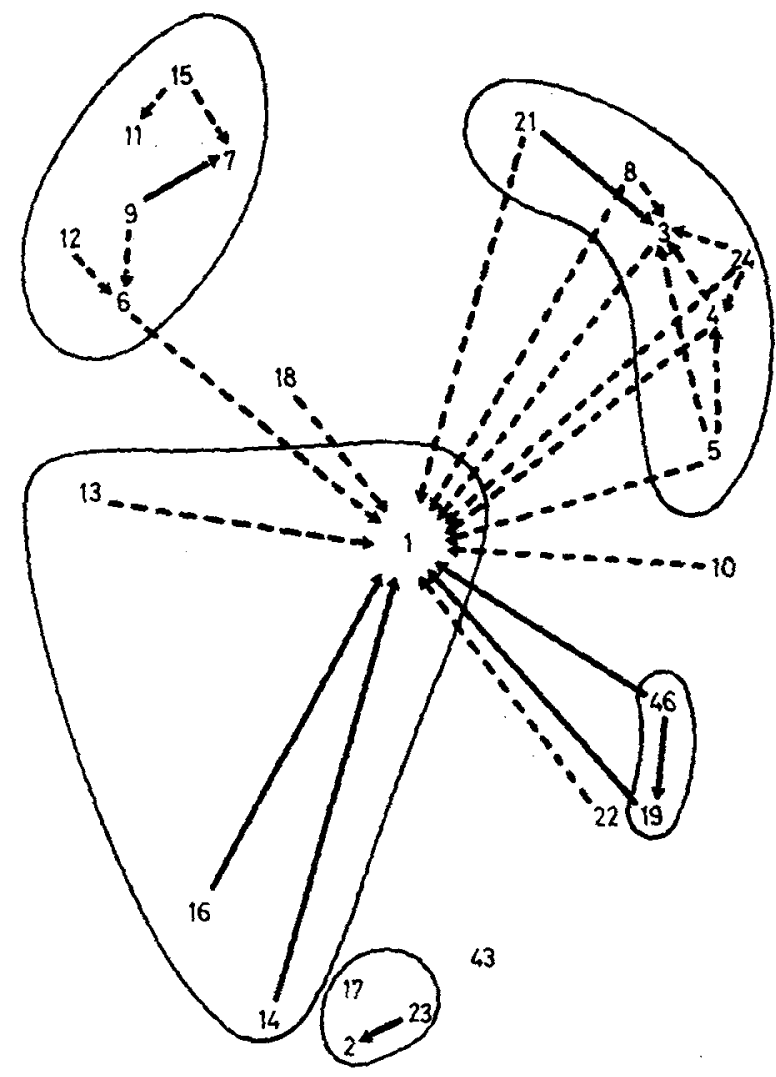

Fig. 6. Zoom map for 1988 Australian geophysics observations. (Plot symbols are given in Table 6)

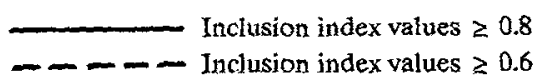

\section{Discussion}

The idea underlying the analysis is that the co-occurrence of subject headings in a set of selected documents can be used to measure and display the degree of association (content relationship) between these headings or topics. Headings are considered as key words (as used in coword analysis) on a higher level of aggregation which have constant meaning even in a cross-subfield context. (Headings could already be related by cross-references introduces by experts). 
Many scientific databases employ more or less developed classification schemes (i.e. with or without cross-references) for assigning documents to different headings. The co-appearance of such headings in a set of preselected documents is used here to represent published Australian research (topics and their links) in geophysics. Links have been further studied by taking subsets of documents with different subject and research characteristics (treatment codes). The INSPEC database appears to be appropriate for this kind of analysis since its records include additional information on type and research characteristics of the source documents (see Table 1).

Representing a subfield structure by headings (instead of highly co-cited publications or words) has some advantages such as explicit content of the headings and simplified selection of the relevant records for the analysis. Nevertheless, it should be used (like all bibliometric techniques) in conjunction with expert opinion or other quantitative methods (co-citation, co-word or other co-unit analyses). Headings are, in general, broader units as compared to keywords or citations. Some additional descriptive capabilities of co-heading analysis (not offered by other techniques and sources) could be mentioned as well:

- Since the file is discipline oriented, a large number of documents, irrespective of their type, source and language of publication, are used in the analysis (for example, problems of biases in favour of more visible journals are avoided).

- Headings are allocated rather uniformly irrespective of the research characteristics of the subfield or of the country of origin.

- The analysis is not restricted to a single topic or speciality (like co-word analysis). It could be extended to cover a whole filed in the selected database. Furthermore, a cross-subfield analysis does not require normalization (needed in cocitation analysis).

- The dynamics of links between headings (and even possible future development of links) could be also studied, since new headings are explicitly introduced in the environment of older ones.

- Headings are easy to access and to process (as compared to citations or keywords).

- Content of headings is explicit and, therefore, the observed links are more open to discussion. Headings are often part of a classification scheme developed on a consensus among experts.

- Time lag is smaller as compared to citation appearance.

- Maps could be simply aggregated by replacing headings of lower classification level with ones of higher level.

- Detailed map (or "zoom" map) of the links of less frequently appearing codes could be generated by taking a subset of documents with appropriate characteristics. 
- A map of national research in a given subfield (or of journal publication profile) could be produced by extracting a subset with given author affiliation (journal title).

Headings are allocated by indexers according to a more or less elaborated classification scheme. However, subjective information is introduced (the so called indexer effect ) which consists mainly in rough assignment (or insufficient depth) and uneven allocation of headings. This effect is attenuated by considering a great number of documents and by the fact that indexers do not know ${ }^{18}$ that subject headings will be used in such (co-heading) analysis for mapping links between topics.

Using an appropriate software (developed for the purpose of the study), six matrices of co-appearance have been constructed. On the diagonal the frequencies of appearance of the headings are placed in descending order. The full size of a matrix is equal to the number of different codes occurring in the selected records. With a view to statistical validity and better representation (by multidimensional scaling), the initial size is reduced by introducing a threshold $C_{t}\left(C_{t}<C_{i i}\right)$. The practical criteria for determining the $C_{t}$ are the amount of information lost and the number of headings (and their links) to be displayed. In Table 7 are given several values for $C_{t}$ and the corresponding percentage of information lost in case all Australian publications in geophysics are considered. Thus, the corresponding matrix contains $60 \%$ of the information and at the same time the analysis could be performed on a personal computer.

Table 7

Dependence of the final display of Australian geophysics (Fig.1) on the treshold value $C_{t}$

\begin{tabular}{lcc}
\hline$C_{t}$ & $\begin{array}{c}\text { Information } \\
\text { lost*\%) }\end{array}$ & $\begin{array}{c}\text { Number of codes } \\
\text { to be displayed }\end{array}$ \\
\hline 1 & 0 & 161 \\
2 & 8 & 97 \\
3 & 15 & 70 \\
4 & 22 & 54 \\
5 & 26 & 46 \\
6 & 34 & 33 \\
7 & 39 & 27 \\
8 & 41 & 25 \\
9 & 46 & 23 \\
\hline
\end{tabular}

*Number of codes not considered (as percentage of the total number of codes used).

The selection of a similarity measure is a compromise between adequate representation of central (frequently appearing) and peripheral topics. 
Correspondingly, more indices could be used:

- Jaccard index: $\mathrm{C}_{\mathrm{ij}} / \mathrm{C}_{\mathrm{ii}}+\mathrm{C}_{\mathrm{jj}}-\mathrm{C}_{\mathrm{ij}}$

- Strength index: $\mathrm{C}_{\mathrm{ij}} / \operatorname{sqrt}\left(\mathrm{C}_{\mathrm{ii}} \mathrm{C}_{\mathrm{jj}}\right)$

- Inclusion index: $C_{i j} / \min \left(C_{i i}, C_{j j}\right)$

- Proximity index: $\mathrm{C}_{\mathrm{ij}} . \mathrm{N} / \mathrm{C}_{\mathrm{ii}} . \mathrm{C}_{\mathrm{jj}}$ with $\mathrm{N}=$ number of selected records, etc.

Here the Inclusion index has been preferred for the following reasons: (a) it has high values even when $C_{j j}$ is low and $C_{i i}$ is high; and (b) its asymmetrical nature is appropriate for graphic representation.

Once the similarity measure is determined, multidimensional scaling has been selected for displaying the structure of Australian geophysics. On Figures 1 to 6 are shown two-dimensional solutions from ALSCAL. On these spatial representations two topics should be further apart the smaller their Inclusion index value is. Since in general two dimensions are not enough to reflect adequately all links (the residual departure from monotonicity or stress is large) it is appropriate to include hierarchical cluster analysis (HCA) as a complementary method for introducing information about grouping of topics. If the stress - value is large, it is also useful to link topics whose similarity (inclusion index) exceeds a selected threshold. In such a case, the multidimensional configuration is used only as a foundation for displaying clustering and graphic results. On Figure 1 a combined map of Australian geophysics is shown: three threshold values are introduced and indicated correspondingly by solid, dashed. and dotted lines. These lines are drawn from topics with lower to such with higher absolute frequency of appearance. Additionally, related topics are enclosed by solid lines (loops) using an appropriate cluster solution. The topics within a cluster should be connected with each other, and poorly connected with those outside the tluster. "The presence of long and haphazardly crossing lines (based on the proximities data) indicates a discrepancy between closeness in the data and closeness in the space."19

\section{Preliminary interpretation of the geophysics maps}

The interpretations of the models (or maps ) consists mainly in identifying clusters of related headings, in determining labels (titles) for them, and in describing some (common) features relevant for revealing the structure in the set of documents under consideration.

Australian publications in geophysics are predominantly domestic, i.e. headings related to Australia prevail in the selected documents. However, a large part of the main topics (as determined by international research) in the subfield (see Table 2) 
are covered. A rather low number of publications deal with interdisciplinary aspects of oceanography which could be also explained with the subject scope of the INSPEC file. Australian papers in geophysics (see Table 3) are mainly experimental (39.8\%) and theoretical (31\%). More than two thirds of the publications (73\%) come from institutes in the Australian Capital Territory, Victoria and New South Wales (see Table 4). Two institutions are particularly active in publishing research results: CSIRO (Commonwealth Scientific and Industrial Research Organization) and the Australian National University (see Table 4). About $90 \%$ of the papers are published in journals. Half of the articles are distributed over eleven journal titles (see Table 5), i.e. articles are rather scattered (as in any applied-oriented subfield of science). Most of the articles are in visible and high impact journals published in the USA, UK, Australia, and the Netherlands.

The map of Australian geophysics (see Fig. 1) displays well the three main subdivision of geophysics : HAG on the left side, SEG on the right, and the GOT between them on the bottom of the figure. No headings from other physics subfields occur: geophysics appears rather as self-contained. This could be explained by the incorporation of external methods or techniques or by indexer effect (insufficient depth of indexation). Instrumentation, computer techniques, and observations play an important role in geophysics research (especially in atmospheric and weather analysis). HAG is represented by one purely atmospheric cluster $(13,14)$. and two closely related hydrospheric clusters $(6,9,12$ and $7,11,15)$. The one could be labelled upper and coastal oceanography and the second is characterized by research on thermohaline structure of the Pacific Ocean and regional sees. These two hydrospheric clusters appear together (are amalgamated) when only experimental publications are considered (see Fig. 2). This means that links within upper and coastal oceanography are different (more theoretical) as compared to the links within the cluster $(7,11,15)$. This appears clearly on Fig. 3 where only theoretical published research is displayed. On this figure only headings from HAG emerge. Three of the four theoretical clusters are linked to Australia.

The three subdivisions of geophysics (SEG, HAG, GOT) have been represented separately by "zoom" or detailed maps correspondingly on Fig. 4 to 6. SEG (see Fig. 4) is represented by five clusters: seismology $(3,21)$; geophysical aspects of geology and mineralogy $(4,5,8,24)$; instrumentation and techniques in explosion seismology $(2,42)$; coastal studies $(6,11,28,37)$; and climatology related to the Pacific Ocean $(1$, $7,18)$.

HAG (see Fig. 5) includes also five clusters: ocean dynamics $(9,15,34,47)$; coastal oceanography $(6,7,28)$; sea-air exchange $(12,13,44)$; boundary layer structure and processes $(25,31)$; and rivers and flows $(1,19,32,45,46)$. 
The structure of GOT is shown on Fig. 6. As mentioned above instrumentation and techniques are largely used in all geophysics subdivisions: atmospheric research $(1,13,14,16)$; hydrospheric research $(6,7,9,12,15)$; solid Earth geophysics $(3,4,5$, $8,21,24)$; rivers and flows research $(19,22,46)$; and especially meteorology $(2,17$, 23).

All maps are derived and discussed here without any substantive knowledge, i.e. without consulting experts in the fields under consideration: Since the method is still partly experimental, the results should be considered critically and taken as preliminary.

\section{Conclusion}

This study has been designed to investigate application (capabilities and limitations) of co-heading analysis and, more specifically, to answer questions such as: Which are the main topics of Australian research in geophysics? How are they related to other headings? How to represent and interpret these links? The answers of these questions have shown the descriptive potential of co-heading analysis. the model supplies valuable (macro-) information on central and peripheral topics in the field under consideration, as well as, on the character and strength of their links. Thus, it provides an alternative view to that of other bibliometric methods and expert judgements. The suitable visualization makes it open for discussion and testing.

The authors would like to thank the referees for useful suggestions and detection of several slips.

\section{References}

1. H. SMALL, E. GarfiELD, The geography of science: disciplinary and national mapping, Joumal of Information Science, 11 (1985) 147-159.

2. P. Healey, H. Rothman, P. K. Hoch, An experiment in science mapping for research planning, Research Policy, 15 (1986) 233-251.

3. D. Hicks, Limitations of co-citation analysis as a tool for science policy, Social Studies of Science, 17 (1987) 295-316.

4. R. R. BRAAM, H. F. MOED, A.F.J. VAN RAAN, Mapping of science: Critical elaboration and new approaches (A Case study in Agricultural Biochemistry), Research Report to RAWB, November (1987).

5. W. M. SHAw (Jr.). Critical thresholds in co-citation graphs, Journal of the American Society for Information Science, 36 (1985) 38-43.

6. R. Todorov, Representing a scientific subfield: A bibliometric approach, Scientometrics, 15 (1989) 593-605. 


\section{R. TODOROV, M. WINTERHAGER: MAPPING AUSTRALIAN GEOPHYSICS}

7. J. E. J. OBERska, Some statistical aspects of co-citation cluster analysis and a judgement by physicists, In: A.F.J. VAN RAAN (Ed.) Handbook of Quantitative Studies of Science and Technology, North- Holland, Amsterdam, (1988). pp. 431-462.

8. H. SmalL, Co-citation in the scientific literature: A new measure of relationship between two documents, Journal of the American Society for Information Science, 24 (1973) 265-269.

9. A. RIP, J.-P. CourTial, Co-word maps of biotechnology: An example of cognitive scientometrics, Scientometrics, 6 (1984) 381- 400.

10. W. L. GuISTI, L. GEORGHIOU, The use of co-nomination analysis in real-time evaluation, Scientometrics, 14 (1988) 265-281.

11. R. TODOROv, Co-classification analysis for science mapping: An example from superconductivity, International Workshop on Science and Technology Indicators, Leiden, November 14-16, (1988).

12. A. Berhelor, P. Clague, S. SChiminovich, W. ZwRner, The ICSU AB International Classification System for Physics: Its history and future, Journal of the American Society for Information Science, 30 (1979) 343-352.

13. J.-P. Courtial, Technical issues and developments in methodology, In: M. Callon, J. LAW, A. RIP (Eds), Mapping the Dynamics of Science and Technology, London; Macmillan, 1986, pp. 189-193.

14. M. Callon, J. Law, A. Rip, Qualitative scientometrics, In: M. Callon, J. LAW, A. RIP (Eds), Mapping the Dynamics of Science and Technology; London, Macmillan, 1986. p. 112.

15. Ibid, p. 114

16. R. N. Shepard, Introduction, In: R.N. Shepard, A.K. Romney, S.B. Nerlove (Eds), Multidimensional Scaling: Theory and Applications in the Behavioural Sciences. V. 1 Theory, New York, Seminar Pr., 1973, pp. 1-20.

17. R. N. SHEPARD, A taxonony of some principal types of data and of multidimensional methods for their analysis, In: R.N. ShEPARD, A.K. ROMNEY, S.B. NERLOVE (Eds), Multidimensional Scaling: Theory and Applications in the Behavioural Sciences. V. 1 Theory, New York, Seminar Pr., 1973, pp. 21-47.

18. D. S. PrICE, The citation cycle, In: B.C. GRIFFITH (Ed.), Key Papers in Information Science, White Plains, N.Y., Knowledge Ind. Publ., 1980, pp. 195-210.

19. J. B. KRUSKAL, M. WISH, Multidimensional Scaling, Beverly Hills, CA: Sage Publications, 1978, p.46. 